\title{
Experimental-Numerical Analysis of Woven Laminates under Tension
}

\author{
Nurrul Amilin ZAINAL ABIDIN 1, 2, Mohd Zairil Hafizi MOHD JAILANI 1,3, \\ Ahmad Kamil HUSSAIN ${ }^{1}$, Jamaluddin MAHMUD ${ }^{1}$ *
}

\author{
${ }^{1}$ Faculty of Mechanical Engineering, Universiti Teknologi MARA, Shah Alam, Selangor, 40450 Malaysia \\ ${ }^{2}$ Faculty of Mechanical Engineering, Universiti Teknologi MARA, Kampus Pasir Gudang, Johor, 81750 Malaysia \\ ${ }^{3}$ Petronas Refinery and Petrochemical Corporation Sdn Bhd (PRPC), Pengerang, Johor, 81600 Malaysia
}

crossref http://dx.doi.org/10.5755/j01.ms.26.4.22898

\section{Received 07 March 2019; accepted 10 July 2019}

\begin{abstract}
Woven composite laminates are rapidly replacing unidirectional composite laminates in terms of structural application. Nevertheless, the deformation theory for woven laminate has not been well established yet, compared to unidirectional laminate. Thus, this paper aims to investigate the deformation behavior of woven laminates under uniaxial tension using both experimental and numerical approaches. The tensile tests were conducted initially according to ASTM D3039 on samples made of $2 \times 2$ twill weave carbon fiber prepared to attain the material constants $\left(E_{1}, E_{2}, G_{12}\right.$ and $\left.v_{12}\right)$ and the deformation behavior which can be obtained from the stress-strain curve. This is important as the material parameters and values should be input correctly to ensure an accurate numerical analysis. The second stage involves the Finite Element Analysis (FEA) using ANSYS and analytical analysis using MATLAB. The results of extension for both numerical approaches have been compared with reference to the experimental results. The results show that the error is less than $30 \%$. The failure analysis also has been performed to determine mode of failure using ANSYS and MATLAB by employing Maximum Stress failure criterion. The displacements during First Ply Failure (FPF) and Last Ply Failure (LPF) between ANSYS and MATLAB showed good correlation where the percentage difference is less than $1 \%$. Therefore, it can be concluded that the current implemented procedure for unidirectional laminates could be a noble alternative approach to simulate woven laminates under tension accurately.
\end{abstract}

Keywords: ANSYS, finite element analysis, MATLAB, uniaxial tensile load, woven composite laminates.

\section{INTRODUCTION}

Woven laminate composites have enticed tremendous attention due to its exceptional mechanical properties, i.e. stiffness, lightweight, and particularly its specific strength and good reinforcement in all directions [ $1-4]$. Through a variety of process methods, laminates can be tailored into many forms and used in extensive applications such as aerospace applications, maritime, transportation industries and civil infrastructures [1,5].

Prior to these wide-ranging applications, especially in the aerospace and ground transportation, the mechanical properties of the composites must be first established and considered. To date, the common experimental techniques employed in studying the mechanical properties of composites are tensile test, compression test, bending test and impact test. However, owing to its anisotropy and nonhomogenous behaviour, which are governed by the complexity of the structure and material characteristics, is exerting pressure to researchers in analysing the laminate mechanical properties in detailed manners [6-8]. The analysis generally includes high-level of mathematical works and numerous governing equations to compute its stiffness, strains and stresses [6]. Deterring this, laboratory tests remain to be the favourable approach in evaluating the absolute strength and predicting the failure of the composite laminates. For the past decades, uniaxial tensile test has been one of the universal experimental methods employed to determine the maximum uniaxial load that a material could withstand, which ultimately establishes the strength of the whole material [9]. Exerting stress beyond its strength capacity will only lead to the structural failure [6].

Nonetheless, the traditional practice of these destructive tests considered challenging and inept, as it requires high cost in preparing the samples and equipment $[5,6,10]$. The utilization of numerical approach is therefore, deemed preferable, hence paved the way to the ideas of generating tremendous databases of engineering properties through suitable predictive models $[6,11]$. By reducing unnecessary destructive tests, finite element simulation emanates as a power tool in condoning a greener approach towards analysing and developing the properties of composite structures via commercial software [6, 12]. Moreover, as a numerical tool, it also permits repetitive calculations and susceptible to adapt any variations in its parameters [13]. A precise assessment and knowledge about the properties of laminate is thus, attainable.

For the past decades, numerous studies have been conducted to explore the mechanical properties of composite woven laminate, experimentally, analytically and numerically $[3-8,10,11,13-16]$. Countless damage models of woven composites were proposed to study and predict the in-plane elastic properties, damage mechanics and failure mechanism of composites laminate $[1,4-8,12,16]$. However, there is paucity in the preceding studies where the failure mechanisms occurred in the woven

\footnotetext{
${ }^{*}$ Corresponding author. Tel.: +603-55436257; fax: +603-55435160

E-mail address: jm@uitm.edu.my (J. Mahmud)
} 
composite has not been successfully predicted by none of these models. It is found that no direct technical approach has been introduced to predict the failure mechanism in woven laminate peculiarly using numerical approach.

Therefore, this study employs an experimentsimulation set up to predict a composite woven laminate failure. The failure load was determined, and the experiment-simulation results were analysed to evaluate the accuracy of the built-in failure criteria. It allows comparison and evaluation of the current simulation results. Previously, the capability of numerical approach using ANSYS software has been performed in predicting the failure load but only for unidirectional composite laminates [6]. Therefore, this study is conducted experimentally and numerically, in order to analyse the deformation behaviour of the new form of composite material. The aim is to determine the main parameters from experiments on the woven composite laminates, so that the parametric values could be input accurately into the finite element models and analytical analysis. This is novel as no similar research and approach has been reported earlier.

\section{METHODOLOGY}

In this study, two approaches were employed; experiment and numerical method. The mechanical properties of woven laminates were first determined in a systematic experimental procedure. Secondly, the Finite Element Analysis using ANSYS and analytical analysis via MATLAB were developed to further investigate the failure mechanism of the tested sample.

Two experiments were conducted; the first experiment aimed to investigate the deformation behaviour of woven laminates and also to determine the value of material constants $\left(E_{1}, E_{2}\right.$ and $\left.v_{12}\right)$. Second experiment was conducted to determine the value of Young's modulus $\left(\mathrm{E}_{45}\right)$ in order to compute the value of shear modulus $\left(G_{12}\right)$. All the results from these experiments were collected and computed for numerical analysis purposes.

The material specimen used was prepreg $3 \mathrm{~K}, 2 \times 2$ HTS40/977-2 Twill Weave Carbon. The reinforcement is a uni-directional (UD) continuous high tensile strength carbon fibre (Toho Tenax HTS40 12 K 800tex) and was preimpregnated with Cycom 977-2 toughended epoxy resin as the matrix. The pre-impregnated HTS40/977-2 tapes were hand lay-up to produce an $0.27 \mathrm{~mm}$ thick eight-ply UP panel and with [0/45/-45/90/90/-45/45/0] lamination scheme. The details are summarized in Table 1. Ten specimens that consist of 8 layers have been fabricated with the same configuration and geometry. The prepreg $2 \times 2$ Twill Weave Carbon Fibre sheet was cut in $300 \mathrm{~mm} \times 200 \mathrm{~mm}$ rectangular shape. There were eight rectangles cut for each angle of laminates. Cutting the warp and weft thread were performed in a proper and detailed manner to ensure the accurate angles of all layers during laying the material $[17,18]$.

Laminates were prepared by stacking technique in which all the prepreg rectangles sheet were stacked one on top of each other at different orientation to give quasiisotropic laminate [0/45/-45/90/90/-45/45/0] [15]. The laminates were pressed on the hot press machine at $154{ }^{\circ} \mathrm{C}$ and $100 \mathrm{bar}$ of pressure for 60 minutes. In order to determine the material constants $E_{1}, E_{2}, G_{12}$ and $v_{12}, 5$ specimens were cut in X-direction and another 5 specimens were cut in $45^{\circ}$ from $\mathrm{X}$-direction. These cutting directions are shown in Fig. 1. These samples then were subjected to tensile load according to the standard test ASTM D3039 [19]. Fig. 2 shows the cutting direction for laminated specimens.

All the test specimens were tested by using INSTRON 3382 Universal Testing Machine at feed rate (testing speed) $2 \mathrm{~mm} / \mathrm{min}$ where the tensile load was increased uniformly [18]. Due to the balance in-plane properties, the woven laminated specimens that are cut in X-direction also represent the specimens for $\mathrm{Y}$-direction which consequently produce the same results [19].

The test specimens were then photographed to analyse the failure modes according to the code that has been codified from previous study [4]. The stress vs. strain curve was plotted and the initial slope of the curve gives the value of Young's modulus while the ratio of transverse strain $\left(\varepsilon_{\mathrm{x}}\right)$ to longitudinal strain $\left(\varepsilon_{\mathrm{y}}\right)$ obtained provides the Poisson's ratio value $\left(v_{12}\right)$. The shear modulus was determined by using the Eq. 1 [3].

$$
\mathrm{G}_{12}=\frac{1}{\frac{4}{E 45}-\frac{1}{E 1}-\frac{1}{E 2}+\frac{2 \mathrm{~V} 12}{E 1}}
$$

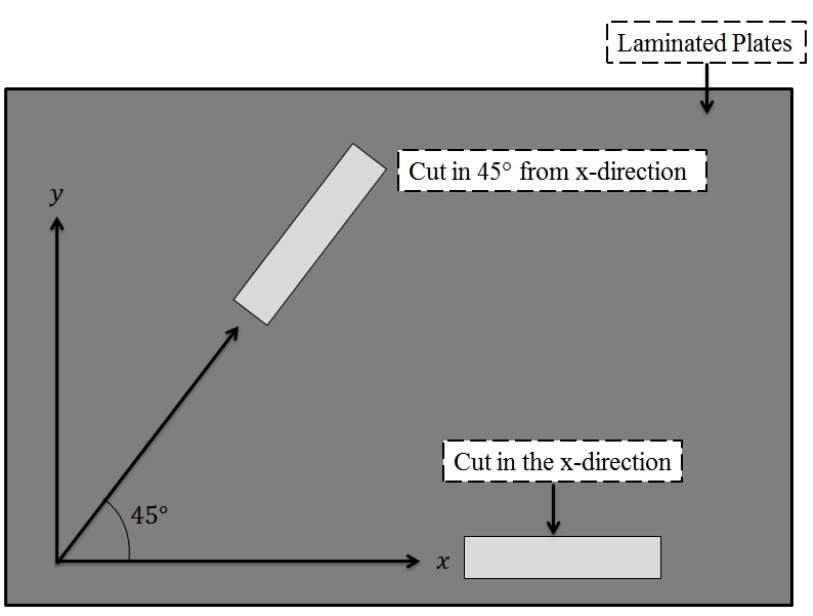

Fig. 1. The cutting direction for laminated specimens

Numerical simulations were performed using two methods which were Finite Element Analysis (FEA) and analytical analysis. In order to simulate the experiment setup, the FEA was developed using ANSYS software to perform the failure analysis of composite laminates. Second analytical analysis was performed by using MATLAB program where the MATLAB code from previous study [6] was modified to compare deformation and failure analysis result between experimental and FEA respectively.

To perform the FEA analysis, the specimens that consist of $0.075 \mathrm{~m} \times 0.015 \mathrm{~m}$ were modelled as quarter of the test specimen in the ANSYS based on the experiment set-up which is shown in Fig. 2. The analysis was performed on a quarter of the composite plate by using 8-noded SHELL element because it is symmetrical geometry [6]. The material orientations used for the FEA model were the same configuration used in the experiment $[0 / 45 /-45 / 90 / 90 /-45 / 45 / 0]$ consists of $1.4 \times 10^{-3} \mathrm{~m}$ 
thickness. The material properties and strength value for the woven laminates used are illustrated in Table 1 which was obtained from the experiment and supplier specification respectively. The element was meshed by using element division is set to $20 \times 10$ mesh. In this analysis, the bottom edge of the test coupon was constrained, and a force was applied to the top edge. The line on the bottom and left edge of the shell were constrained in the y-direction and $\mathrm{x}$ direction respectively. The node at the bottom corner was constrained in all degrees of freedom. The force was distributed uniformly across the right edge line of the shell. This model is an idealized based on the tension test experiment.

Table 1. Material properties for woven laminates

\begin{tabular}{|c|c|c|c|}
\hline Properties & Values & Properties & Values, MPa \\
\hline$E_{1}$ & $15.93 \mathrm{GPa}$ & $\mathrm{X}_{\mathrm{T}}$ & 73.77 \\
\hline$E_{2}$ & $15.93 \mathrm{GPa}$ & $\mathrm{X}_{\mathrm{c}}$ & 73.77 \\
\hline$G_{12}$ & $7.51 \mathrm{GPa}$ & $\mathrm{Y}_{\mathrm{T}}$ & 73.77 \\
\hline$v_{12}$ & 0.26 & $\mathrm{Y}_{\mathrm{c}}$ & 73.77 \\
\hline Ply thickness, $h i$ & $1.75 \times 10^{-4} \mathrm{~mm}$ & $\mathrm{~S}$ & 50 \\
\hline
\end{tabular}

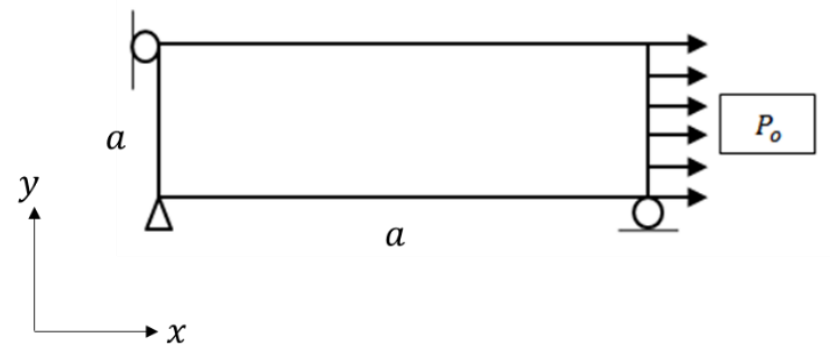

Fig. 2. Uniaxial tensile model (quarter test specimen)

Based on the theoretical laminate analysis, the analytical analysis for deformation and failure analysis was performed using MATLAB software where all the values of the laminate geometry and material properties were inserted in the MATLAB script. The laminate thickness and number of ply as well as laminate orientation also needed to be included. Then, after the load for x-direction was inserted, all parameters for [Q] [A] [B] [D] matrix, normal stress, normal strain were automatically calculated. The failure analysis of each ply of composite laminate was determined using maximum stress failure criteria. The failure of the composite laminate was detected based on the index displayed. If the index is equal or greater than one, the laminate is considered fail. The principle stress is used in order to determine the failure mode of the lamina.
Numerical validation is essential to determine if the current numerical approach is acceptable or not. In this study, the validation was carried out by comparing deformation results between ANSYS and MATLAB. From the previous study [6], the deformation analysis for ANSYS was determined based on the Maximum Stress criteria consisted different orientations under uniaxial loading condition. The element type used in this model was SHELL 181 and the boundary condition of the model is represented in Fig. 2 that shows a quarter tension model.

The geometry of the laminated plate is square where the length of the plate is equal to the width of the plate that is $a=0.02 \mathrm{~m}$. The laminated plate is made of T300/5208 Graphite/Epoxy having an aspect ratio $(\mathrm{S}=a / h)$ and the specific material properties is as shown in the Table 2. Hence, the thickness, $h$ and the cross-sectional area $(A=a h)$ of the laminated plated were calculated as $1.3333 \times 10^{-4} \mathrm{~m}$ and $2.6667 \times 10^{-6} \mathrm{~m}^{2}$ respectively.

There were 24 layers of laminated plate where the layup studied was $\left(\theta_{4} / 0_{4} /-\theta_{4}\right)$ s. Meanwhile, the deformation analysis for MATLAB was performed by inserting the laminate geometry and material properties in the MATLAB script.

Table 2. Material and Strength properties of T300/5208 graphiteepoxy [16]

\begin{tabular}{|c|c|c|c|}
\hline Properties & Values & Properties & Values, MPa \\
\hline$E_{1}$ & $138 \mathrm{GPa}$ & $\mathrm{X}_{\mathrm{T}}$ & 1450 \\
\hline$E_{2}=E_{3}$ & $10.6 \mathrm{GPa}$ & $\mathrm{X}_{\mathrm{c}}$ & 1450 \\
\hline$G_{12}$ & $6.46 \mathrm{GPa}$ & $\mathrm{Y}_{\mathrm{T}}$ & 51 \\
\hline$v_{12}=v_{13}=v_{23}$ & 0.24 & $\mathrm{Y}_{\mathrm{c}}$ & 250 \\
\hline & & $\mathrm{S}_{\mathrm{A}}=\mathrm{S}_{\mathrm{T}}=\mathrm{S}_{\mathrm{Z}}$ & 93 \\
\hline
\end{tabular}

The data of displacement obtained for both numerical approaches are tabulated in the Table 3 . The deformation analysis of the laminated plate was analysed based on the variation of laminate scheme that varies from $0^{\circ}$ to $90^{\circ}$ with a constant load. Based on the layup studied, the analysis begins with the orientation of fibre, where the angle, $\theta$ starts with $0^{\circ}$ and varies with the step-size of $15^{\circ}$ until $90^{\circ}$. Table 3 shows that only small difference results of displacement between ANSYS and MATLAB during the analysis for angle $0^{\circ}, 15^{\circ}, 30^{\circ}, 45^{\circ}, 75^{\circ}$ and $90^{\circ}$. Therefore, these numerical approaches were considered valid to be used for this study.

The accuracy between FEA and analytical analysis is determined by comparing the numerical results of ANSYS to MATLAB. The percentage difference of result is computed using Eq. 2 which MATLAB results are taken as a reference [20].

Table 3. Comparison of displacement between MATLAB and ANSYS

\begin{tabular}{|c|c|c|c|c|c|c|c|}
\hline \multirow[b]{2}{*}{ Angle } & \multirow[b]{2}{*}{ Load, N } & \multicolumn{2}{|c|}{ MATLAB } & \multicolumn{2}{|c|}{ ANSYS } & \multirow[b]{2}{*}{$\begin{array}{l}\% \text { Difference for } \\
\text { Displacement-X }\end{array}$} & \multirow[b]{2}{*}{$\begin{array}{l}\% \text { Difference for } \\
\text { Displacement-Y }\end{array}$} \\
\hline & & $\begin{array}{l}\text { Displacement-X, } \\
\mathrm{mm}\end{array}$ & $\begin{array}{l}\text { Displacement-Y, } \\
\mathrm{mm}\end{array}$ & $\begin{array}{l}\text { Displacement- } \\
\mathrm{X}, \mathrm{mm}\end{array}$ & $\begin{array}{l}\text { Displacement-Y, } \\
\mathrm{mm}\end{array}$ & & \\
\hline $0^{\circ}$ & 687 & 0.0374 & -0.011 & 0.0373 & -0.011 & 0.27 & 0 \\
\hline $15^{\circ}$ & 687 & 0.0420 & \begin{tabular}{|l}
-0.029 \\
\end{tabular} & 0.042 & -0.029 & 0 & 0.34 \\
\hline $30^{\circ}$ & 687 & 0.0610 & -0.062 & 0.061 & -0.062 & 0 & 0.16 \\
\hline $45^{\circ}$ & 687 & 0.0840 & -0.056 & 0.084 & -0.056 & 0 & 0.18 \\
\hline $60^{\circ}$ & 687 & 0.0940 & -0.028 & 0.094 & -0.027 & 0 & 0.36 \\
\hline $75^{\circ}$ & 687 & 0.0964 & -0.009 & 0.0963 & -0.009 & 0.10 & 0.11 \\
\hline $90^{\circ}$ & 687 & 0.0966 & -0.003 & 0.0965 & -0.003 & 0.10 & 0.31 \\
\hline
\end{tabular}


Percentage difference $=$

$$
\frac{\operatorname{Result}(\text { ANSYS })-\text { Result }(M A T L A B)}{\text { Result }(\text { MATLAB })} \times 100
$$

The error analysis between experimental-numerical was calculated using Eq. 3 which the experiment results were taken as reference [20].

Error $=$

Result (ANSYS or MATLAB) - Experimental Result Experimental Result $\times 100$

\section{RESULTS AND DISCUSSION}

Table 4 focuses on the tested specimen where based on visual inspection, the type of failure is classified referring to code proposed by [21]. From the experiments, it was observed that only three specimens failed inside the gage length while the other two failed at the gripping length. Four of the specimens failed with lateral type (Samples 1, 2, 3 and $5)$ but only one specimen failed with angled type (Sample 3). No occurrence of failure by edge delamination and/or shear was found.

Consequently, the tested specimens failed due to the stress concentration at this gripping length, which is existed from compressive force of the grip. This finding has also been observed in the previous study [22]. However, the observation was also compared with the previous study where the result displayed the same type of failure [21]. Therefore, the tested specimens in this study can be considered credible and be used to compute the material constants for the further analytical analysis.
The output data from tensile tests were depicted as loadextension diagram (Fig. 3) and stress-strain diagram (Fig. 4) for the $[0 / \pm 45 / 90]$ laminate cut along $\mathrm{x}$-direction. The curves for the five specimens are shown and a curve representing the average value is highlighted. The end of the curves in Fig. 3 indicates the failure load, contributing to the laminate breakage. Nonlinearity characteristic can be observed in the stress-strain relation (Fig. 4) before failure, which possibly due to the anisotropic behavior of the woven laminate made of fiber reinforced in polymeric matrix materials. The similar characteristic of woven laminates composite has been reported by Khoshbakht and colleague [18] but in this study the initial loading steps $(<1$ percent strain) were not consistent. Owing to this, the affected data were excluded when approximating the Young's modulus based on the average values.

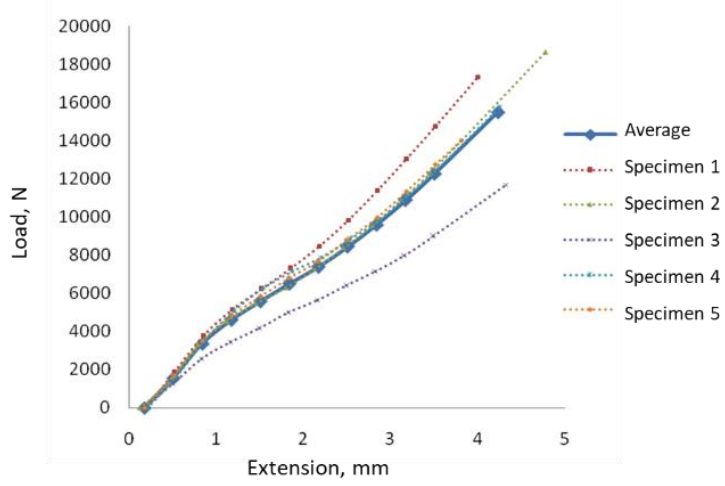

Fig. 3. Load-extension curves of 5 specimens obtained from the uniaxial tensile test

Table 4. Specimen inspection (cut in X-direction) based on failure modes

\begin{tabular}{|c|c|c|}
\hline Failure types & Tested specimen & Detail of the failure types \\
\hline \multirow{6}{*}{ Lateral Inside grip/tab Top (LIT) } & Sample 1 & \\
\hline & Sample 2 & \\
\hline & & \\
\hline & Sample 4 & \\
\hline & Sample 5 & \\
\hline & Sample 3 & \\
\hline Angled Inside grip/tab Bottom (AIB) & & \\
\hline
\end{tabular}




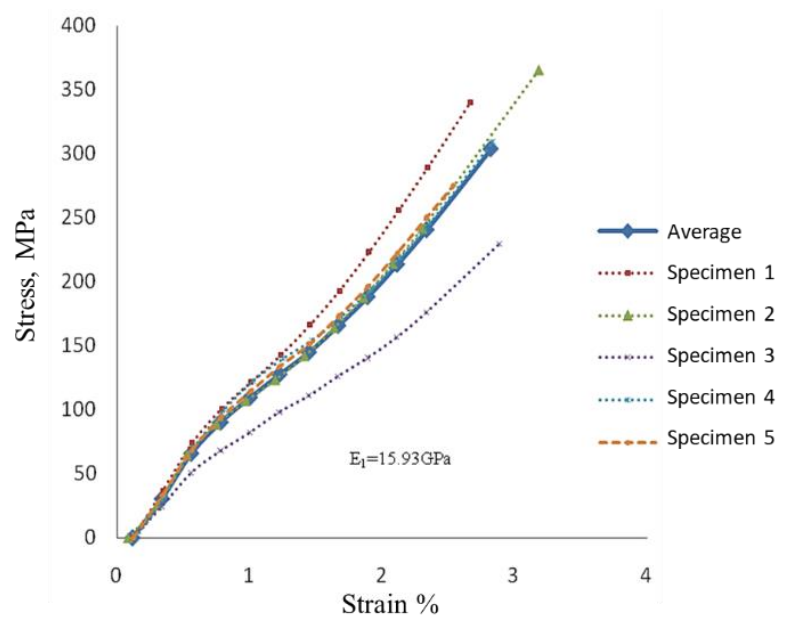

Fig. 4. Stress-strain curves of the 5 specimens plotted from the uniaxial tensile test

From the slope of the stress-strain curve, it conveys the value of Young's modulus, $E_{1}$ for longitudinal direction which equal to $15.93 \mathrm{GPa}$ and this value also represents the value of Young's modulus for transverse direction, $E_{2}$.

This is because as reported from previous study, woven composite laminates have the phenomenological properties which in-plane properties are balanced so that the value of Young' modulus for woven composite laminates are equal for longitudinal and transverse direction [19]. Hence, the value of $E_{1}$ and $E_{2}$ obtained from the experimental methods were valid to be used for further numerical analysis.

Table 5 shows the output data determined from the tested specimens. The value of Young's modulus for each specimen is obtained directly from the linear region below $1 \%$ strain of the stress-strain curve. The value of extension shows in the Table 5 was obtained from the raw data which represents the last deformation value as the specimen impends to breakage. The contraction value in $\mathrm{x}$-direction is determined by measuring the change in the width.

After computing the value of strain in transverse, $\varepsilon_{\mathrm{y}}$ and longitudinal Strain, $\varepsilon_{\mathrm{x}}$, then value of Poisson' ration, $v_{12}$ of each tested specimen can be determined. It should be noted that only the average value of the Poisson' ratio $v_{12}$ is required to determine the shear modulus, $G_{12}$ value. However, another important step before calculating the shear modulus $G_{12}$ value is done by computing the average value of Young's modulus, $E_{45}$ (specimen was cut in $45^{\circ}$ from $\mathrm{x}$-direction). This value can be obtained from the slope of average stress-strain graph for the tested specimens that are cut in $45^{\circ}$ from $\mathrm{x}$-direction. Then, the value for shear modulus $G_{12}$ is calculated by using the shear modulus formula. Table 6 shows the final value of four material constants which are required before starting the numerical analysis.

Table 6. Material constant of woven carbon fibre

\begin{tabular}{|c|c|}
\hline Material constant & Value \\
\hline$E_{1}=E_{2}, \mathrm{GPa}$ & 15.93 \\
\hline$G_{12}, \mathrm{GPa}$ & 7.51 \\
\hline$v_{12}$ & 0.26 \\
\hline
\end{tabular}

The results shown in Table 7 display the results of load versus extension comparing between experiment, ANSYS and MATLAB program. The numerical analysis was begun with gathering several loads from experiment as input data to predict the extension value. Then, 10 different loadextension values were collected from the average of experiment data were compared with the numerical results.

Fig. 5 compares the load-extension curve between the numerical approach and the actual data from experiment. The load-extension curves for ANSYS and MATLAB are almost coincided and show a linear behavior. In this analysis, the percentage error of extension value is computed as stated in the Eq. 3.

From the error analysis of the extension value, it is considered valid result, as the error is below than 30 percent [6]. It should be noted that, the error from the Table 7 is significantly increased after the input load is about $5592.7426 \mathrm{~N}$. However, the error started to decrease after load of $10897.0112 \mathrm{~N}$ until the maximum load is applied. It is vital to note that the non-linear behavior of the loadextension graph is the factor that affects the difference in the error.

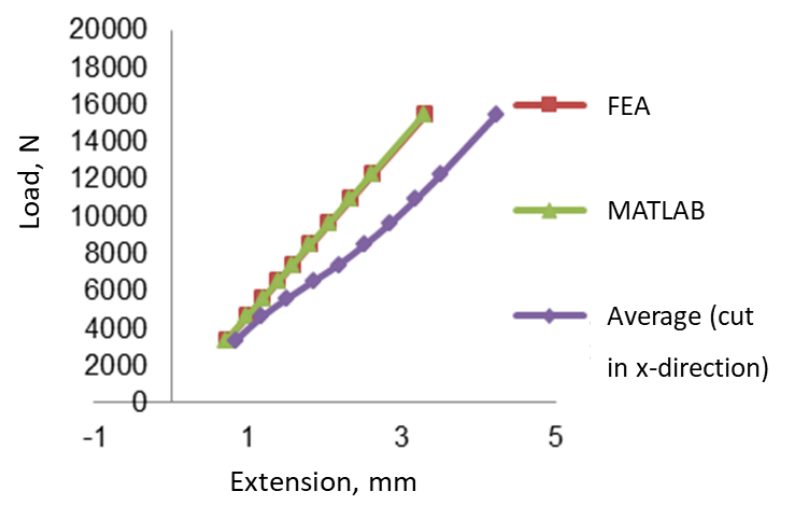

Fig. 5. Comparison of the load-extension curves acquired from both experimental and numerical results

Table 8 shows the comparison of displacement in $\mathrm{x}$ direction and y-direction between ANSYS software and MATLAB program for FPF and LPF analysis respectively. In the analysis of FPF, the load at which the modeled specimen starts to fail is about $1618.72 \mathrm{~N}$ for ANSYS and 1618.73 $\mathrm{N}$ for MATLAB as stated.

Table 5. Output data for the test specimens that were cut in $\mathrm{x}$-direction

\begin{tabular}{|c|c|c|c|c|c|c|}
\hline Specimen & $\begin{array}{c}\text { Young's modulus } E_{1}, \\
\mathrm{GPa}\end{array}$ & $\begin{array}{c}\text { Extension in } \\
\text { y-direction, } \mathrm{mm}\end{array}$ & $\begin{array}{c}\text { Contraction in } \\
\text { x-direction, } \mathrm{mm}\end{array}$ & Strain $\varepsilon_{\mathrm{y}}, \Delta L / L$ & Strain $\varepsilon_{\mathrm{y}}, \Delta W / W$ & $\begin{array}{c}\text { Poisson's } \\
\text { ratio, } v_{12}\end{array}$ \\
\hline 1 & 16.87 & 3.997 & -0.2133 & 0.027 & $-7.1 \times 10^{-3}$ & 0.26 \\
\hline 2 & 17.74 & 4.777 & -0.2417 & 0.032 & $-8.0 \times 10^{-3}$ & 0.25 \\
\hline 3 & 11.86 & 4.323 & -0.2311 & 0.029 & $-7.7 \times 10^{-3}$ & 0.27 \\
\hline 4 & 17.43 & 4.253 & -0.2194 & 0.028 & $-7.3 \times 10^{-3}$ & 0.26 \\
\hline 5 & 15.79 & 3.810 & -0.2137 & 0.025 & $-7.1 \times 10^{-3}$ & 0.28 \\
\hline
\end{tabular}


Table 7. Results of the load versus extension obtained from the experiments, ANSYS and MATLAB

\begin{tabular}{|c|c|c|c|c|c|}
\hline \multirow{2}{*}{ Load, N } & \multicolumn{3}{|c|}{ Extension } & \multicolumn{2}{c|}{ \% Error } \\
\cline { 2 - 6 } & Experiment & ANSYS & MATLAB & Experiment and ANSYS & Experiment and MATLAB \\
\hline 1 & 16.87 & 3.997 & -0.2133 & 0.027 & $-7.1 \times 10^{-3}$ \\
\hline 2 & 17.74 & 4.777 & -0.2417 & 0.032 & $-8.0 \times 10^{-3}$ \\
\hline 3 & 11.86 & 4.323 & -0.2311 & 0.029 & $-7.7 \times 10^{-3}$ \\
\hline 4 & 17.43 & 4.253 & -0.2194 & 0.028 & $-7.3 \times 10^{-3}$ \\
\hline 5 & 15.79 & 3.810 & -0.2137 & 0.025 & $-7.1 \times 10^{-3}$ \\
\hline
\end{tabular}

Table 8. Comparison of the displacement between ANSYS and MATLAB (FPF Analysis)

\begin{tabular}{|c|c|c|c|c|c|}
\hline $\begin{array}{c}\text { Numerical } \\
\text { approach }\end{array}$ & Failure load, $\mathrm{N}$ & $\begin{array}{c}\text { Pressure on line, } \\
\mathrm{Nm}\end{array}$ & \multirow{2}{*}{ Lamina failure } & \multicolumn{2}{|c|}{ Displacement, $\mathrm{mm}$} \\
\hline ANSYS & 1618.72 & 107914.76 & $1,4,5,8$ & X-displacement & Y-displacement \\
\hline MATLAB & 1618.73 & 107915.33 & $1,4,5,8$ & 0.344 & -0.01490 \\
\hline \multicolumn{2}{|r}{} & Difference & $0.345 \%$ & -0.01494 \\
\hline
\end{tabular}

Table 9. Comparison of the displacement between ANSYS and MATLAB (LPF Analysis)

\begin{tabular}{|c|c|c|c|c|c|}
\hline $\begin{array}{c}\text { Numerical } \\
\text { approach }\end{array}$ & Failure Load, $\mathrm{N}$ & $\begin{array}{c}\text { Pressure on line, } \\
\mathrm{Nm}\end{array}$ & Lamina failure & \multicolumn{2}{c|}{ Displacement, mm } \\
\cline { 4 - 6 } & & 128921.45 & $2,3,6,7$ & X-displacement & Y-displacement \\
\hline ANSYS & 1933.82 & 128923.33 & $2,3,6,7$ & 0.4100 & -0.0179 \\
\hline MATLAB & 1933.85 & & Difference & 0.4125 & $-0.01 \% 0$ \\
\hline \multicolumn{3}{|r|}{} & & $0.61 \%$ & $0.56 \%$ \\
\hline
\end{tabular}

The LPF load indicates the modeled specimen required a higher amount of load to fail and has taken place when failure index of any failure is lager or equal to one [6]. At this load applied, the laminate failure for the FPF and LPF analysis is observed by checking the index number which failure index is equal to one [20]. The number $1,4,5,8$ and $2,3,6,7$ in the column lamina failure represent the layer number at which the failure occurred. From the analysis, the displacement value is characterized in two directions which are $\mathrm{x}$-direction and y-direction.

The result of displacement for FPF and LPF analysis are tabulated in the Table 8 and Table 9 respectively. It is remarkable to note that the value of displacement in $\mathrm{x}$ direction and $y$-direction shows good correlation between ANSYS and MATLAB which the error is less than one percent, which is also observed in previous study [20]. The differences for $\mathrm{x}$-displacement and $\mathrm{y}$-displacement are computed using Eq. 2 which MATLAB results used as a reference. In this analysis, the displacement obtained for
LPF is higher compared to the FPF analysis which its displacement would be depending on the load applied.

The first step in determining the mode of failure starts with governing the principle stress of FPF and LPF for both numerical approaches. The results given by ANSYS are only displayed the stresses in global coordinate directions of each layer. Therefore, the stress value for ANSYS is needed to be transformed into principle stress to compare with the MATLAB results. It is only simple transformation in which the value of stresses obtained from ANSYS is inserted in the MATLAB script.

The Table 10, Table 11, Table 12 and Table 13 demonstrate the good correlation between ANSYS and MATLAB for the principal stress results. The results of transformation of stress (ANSYS) for FPF and LPF are tabulated in the Table 10 and Table 12 respectively. Obtaining the value of principle stress paves the ways to identify the mode of failure of each layer failed.

Table 10. Principle stress of lamina failure from ANSYS (FPF Analysis)

\begin{tabular}{|c|c|c|c|c|c|}
\hline \multirow{2}{*}{$\begin{array}{c}\text { Lamina } \\
\text { failure }\end{array}$} & \multirow{2}{*}{ Angle, } & \multicolumn{2}{|c|}{ Principle stress (ANSYS) using MATLAB to transform the normal } & \multirow{2}{*}{ Failure mode } \\
\cline { 3 - 5 } & & Stress-1, MPa & Stress-2, MPa & Stress-3, MPa & \\
\hline 1 & 0 & 73.80 & 3.310 & $1.02 \times 10-11$ & Fibre/Matrix fail in tension \\
\hline 4 & 90 & 3.310 & 73.80 & $-1.02 \times 10-11$ & Matrix/Fibre fail in tension \\
\hline 5 & 90 & 3.310 & 73.80 & $-1.02 \times 10-11$ & Matrix/Fibre fail in tension \\
\hline 8 & 0 & 73.80 & 3.310 & $1.02 \times 10-11$ & Fibre/Matrix fail in tension \\
\hline
\end{tabular}

Table 11. Principle stress of lamina failure from MATLAB (FPF Analysis)

\begin{tabular}{|c|c|c|c|c|c|}
\hline \multirow{2}{*}{$\begin{array}{c}\text { Lamina } \\
\text { failure }\end{array}$} & \multirow{2}{*}{ Angle,${ }^{\circ}$} & \multicolumn{2}{|c|}{ Principle stress (ANSYS) using MATLAB to transform the normal } & \multirow{2}{*}{ Failure mode } \\
\cline { 3 - 5 } & & Stress-1, MPa & Stress-2, MPa & Stress-3, MPa & \\
\hline 1 & 0 & 73.77 & 3.319 & $4.243 \times 10-16$ & Fibre/Matrix fail in tension \\
\hline 4 & 90 & 3.319 & 73.77 & $-3.175 \times 10-15$ & Matrix/Fibre fail in tension \\
\hline 5 & 90 & 3.319 & 73.77 & $-3.175 \times 10-15$ & Matrix/Fibre fail in tension \\
\hline 8 & 0 & 73.77 & 3.319 & $4.243 \times 10-16$ & Fibre/Matrix fail in tension \\
\hline
\end{tabular}


Table 12. Principle stress of lamina failure from ANSYS (LPF Analysis)

\begin{tabular}{|c|c|c|c|c|c|}
\hline \multirow{2}{*}{ Lamina failure } & \multirow{2}{*}{ Angle, ${ }^{\circ}$} & \multicolumn{2}{|c|}{ Principle stress (ANSY) using MATLAB to transform the normal stress } & \multirow{2}{*}{ Failure mode } \\
\cline { 3 - 5 } & 45 & Stress-1, MPa & Stress-2, MPa & Stress-3, MPa & Shear fail \\
\hline 2 & 46.00 & 46.00 & -50 & Shear fail \\
\hline 3 & -45 & 46.00 & 46.00 & 50 & Shear fail \\
\hline 6 & -45 & 46.00 & 46.00 & -50 & Shear fail \\
\hline 7 & 45 & 46.00 & 46.00 & -50 & \\
\hline
\end{tabular}

Table 13. Principle stress of lamina failure from MATLAB (LPF Analysis)

\begin{tabular}{|c|c|c|c|c|c|}
\hline \multirow{2}{*}{ Lamina failure } & \multirow{2}{*}{ Angle ${ }^{\circ}$} & \multicolumn{2}{|c|}{ Principle stress (ANSYS) using MATLAB to transform the normal stress } & \multirow{2}{*}{ Failure mode } \\
\cline { 3 - 5 } & 45 & Stress-1, MPa & Stress-2, MPa & Stress-3, MPa & Shear fail \\
\hline 2 & 46.044 & 46.044 & -50.001 & Shear fail \\
\hline 3 & -45 & 46.044 & 46.044 & 50.001 & Shear fail \\
\hline 6 & -45 & 46.044 & 46.044 & 50.001 & Shear fail \\
\hline 7 & 45 & 46.044 & 46.044 & -50.001 & \\
\hline
\end{tabular}

All the tables below indicate the mode of failure corresponding to the principle stress in direction-1, direction-2 and direction-12 for both failure analyses.

For the FPF analysis, it shows that Fibre/Matrix failure in tension occurred at layer 1 and layer 8 of laminate at angle of $0^{\circ}$. In general, fibre failure in tension occurred when the principle stress, $\sigma 1$ reached the longitudinal strength in tension, $X_{\mathrm{T}}[2]$.

Theoretically, woven laminates owing balanced inplane properties which the fibre and matrix are exists in the direction-1. Hence, from this analysis the mode of failure can be fibre or matrix failure in tension. However, layer 4 and layer 5 of laminate at angle of $90^{\circ}$ showed the Matrix/Fibre failure in tension at which the value of principle stress, $\sigma_{2}$ is higher compared to the transverse strength, $Y_{\mathrm{T}}$ [2]. When the matrix failed in the direction-2, the fibre that exists in that layer also failed due to the characteristic of woven composite material.

The LPF analysis is much more interesting than FPF analysis because all the layers are failed in shear. The LPF occurs at the layer 2, 3, 6, and 7 which consisting the angle of $45^{\circ}$ and $-45^{\circ}$. All these angles make the laminates stronger because it makes up the large volume percentage of the laminate [16]. As shown in the Table 12 and Table 13, the good correlation of principle stress value also obtained between ANSYS and MATLAB. From the results obtained, the shear fails for all layers occurred due to the value of principle stress $\tau_{12}$ is higher than value of shear strength, $S$ [2].

\section{CONCLUSIONS}

The extension results obtained from the experiment and numerical analysis have shown a good agreement. The analysis shows that both numerical approaches offered a more realistic and reliable results where the result obtained from the FEA are in similar with the analytical approach. Moreover, the results of principle stress also indicated that both numerical approaches could be used in order to determine the failure mode of woven laminates when subjected to uniaxial load. Therefore, this study explained the details of the experimental and numerical analysis to give a better understanding about the behaviour of woven laminates composite. The experiment results obtained directly will provide a reference data that can be used for future study.
The failure analysis of composite laminate using numerical approach is important because it could provide an accurate result especially for the development of composite industry. This analysis also gives huge advantages for engineers to design an optimum load or stress depending on the applications. Therefore, a comprehensive understanding about the deformation behaviour of woven laminates composite is thus needed.

\section{Acknowledgments}

This research is funded by the Ministry of Education (MOE) of Malaysia and Universiti Teknologi MARA Malaysia, UiTM grant no. 600-RMI/FRGS 5/3 (165/2019) and $\mathrm{KPM} \quad-\quad$ reference number FRGS/1/2018/TK03/UITM/02/8).

\section{REFERENCES}

1. Alonso, L., Navarro, C., García-Castillo, S.K. Analytical Models for The Perforation of Thick and Thin Thickness Woven-Laminates Subjected to High-Velocity Impact Composites Part B: Engineering 143 2018: pp. 292-300. https://doi.org/10.1016/j.compositesb.2018.01.030

2. Jones, R.M. Mechanics of Composite Materials. CRC press 2014.

3. Wu, L., Guo, Y.N., Li, Y.L. An Experimental Study on the Mechanical Performance and Damage Evolution of Woven Fabric E-glass Fiber Reinforced Epoxy Composite Key Engineering Materials 417 2010: pp. 137-140. https://doi.org/10.4028/www.scientific.net/KEM.417418.137

4. Kam, C.Z. Finite Element Formulation for Composite Laminate Plates with Degenerated Interface, Doctoral dissertation, Universiti Teknologi Malaysia, 2011.

5. Tong, G., Liu, T.F. Finite Element Analysis of Woven Fabric Laminates Structural Strength Advanced Materials Research 785 2013: pp. 199-203. https://doi.org/10.4028/www.scientific.net/AMR.785786.199

6. Mahmud, J., Hussain, A.K., Rahimi, N., Rahim, M.A. Failure Analysis of Composite Laminate Based on Experiment-Simulation Integration Current Research in Malaysia 2 2013: pp. 7-22.

7. Takeda, T., Takano, S., Shindo, Y., Narita, F. Deformation and Progressive Failure Behavior of Woven-FabricReinforced Glass/Epoxy Composite Laminates under Tensile 
Loading at Cryogenic Temperatures Composites Science and Technology $65(11-12)$ 2005: pp. 1691-1702. https://doi.org/10.1016/j.compscitech.2005.02.009

8. Zako, M., Uetsuji, Y., Kurashiki, T. Finite Element Analysis of Damaged Woven Fabric Composite Materials Composites Science and Technology $63(3-4)$ 2003: pp. $507-516$. https://doi.org/10.1016/S0266-3538(02)00211-7

9. Daniel, I.M., Ishai, O., Daniel, I.M., Daniel, I. Engineering Mechanics of Composite Materials, New York: Oxford University Press 3 1994: pp. 256-256.

10. Soni, S. A New Look at Commonly Used Failure Theories in Composite Laminates 24th Structures, Structural Dynamics and Materials Conference 1983: pp. 837. https://doi.org/10.2514/6.1983-837

11. Callus, P.J., Mouritz, A.P., Bannister, M.K., Leong, K.H. Tensile Properties nd Failure Mechanisms of 3D Woven GRP Composites Composites Part A: Applied Science and Manufacturing 30 (11) 1999: pp. 1277-1287. https://doi.org/10.1016/S1359-835X(99)00033-0

12. González, E.V., Maimí, P., Martín-Santos, E., Soto, A., Cruz, P., de la Escalera, F.M., de Aja, J.S. Simulating Drop-Weight Impact and Compression after Impact Tests on Composite Laminates Using Conventional Shell Finite Elements International Journal of Solids and Structures 144 2018: pp. 230-247. https://doi.org/10.1016/j.ijsolstr.2018.05.005

13. Akbulut, M., Sonmez, F.O. Optimum Design of Composite Laminates for Minimum Thickness Computers \& Structures 86 (21-22) 2008: pp. 1974-1982. https://doi.org/10.1016/j.compstruc.2008.05.003

14. Ekșı, S., Genel, K. Comparison of Mechanical Properties of Unidirectional and Woven Carbon, Glass and Aramid Fiber Reinforced Epoxy Composites Composites 132 2017: pp. $879-882$.

http://doi.org/10.12693/APhysPolA.132.879
15. Mortazavian, S., Fatemi, A. Effects of Fiber Orientation and Anisotropy on Tensile Strength and Elastic Modulus of Short Fiber Reinforced Polymer Composites Composites Part B: Engineering 72 2015: pp. 116-129. https://doi.org/10.1016/j.compositesb.2014.11.041

16. Tolson, S., Zabaras, N. Finite Element Analysis of Progressive Failure in Laminated Composite Plates Computers \& Structures 38 (3) 1991: pp. 361-376. https://doi.org/10.1016/0045-7949(91)90113-Z

17. Khashaba, U.A., Aldousari, S.M., Najjar, I.M.R. Behavior of [0] 8 Woven Composites Under Combined Bending and Tension Loading: Part-I Experimental and Analytical Journal of Composite Materials 46 (11) 2012: pp. $1345-1355$. https://doi.org/10.1177\%2F0021998311418390

18. Khoshbakht, M., Chowdhury, S.J., $\quad$ Seif, M.A., Khashaba, U.A. Failure of Woven Composites Under Combined Tension-Bending Loading Composite Structures 90 (3) 2009: pp. 279-286. https://doi.org/10.1016/j.compstruct.2009.02.012

19. Mishra, I. Parametric Instability of Woven Fiber Composite Plates 2012 (Doctoral dissertation).

20. Rahimi, N., Hussain, A.K., Meon, M.S., Mahmud, J. Capability Assessment of Finite Element Software in Predicting the Last Ply Failure of Composite Laminates Procedia Engineering 41 2012: pp. 1647-1653. https://doi: 10.1016/j.proeng.2012.07.363

21. Paiva, J.M.F.D., Mayer, S., Rezende, M.C. Comparison of Tensile Strength of Different Carbon Fabric Reinforced Epoxy Composites Materials Research 9(1) 2006: pp. $83-90$. http://dx.doi.org/10.1590/S1516-14392006000100016

22. Khashaba, U.A., Seif, M.A. Effect of Different Loading Conditions on the Mechanical Behavior of [0/ $\pm 45 / 90] \mathrm{s}$ Woven Composites Composite Structures 74 (4) 2006: pp. $440-448$. https://doi.org/10.1016/j.compstruct.2005.04.024 